American J. of Engineering and Applied Sciences 4 (3): 390-399, 2011

ISSN 1941-7020

(C) 2014 O.B.H.B. Kechiche et al., This open access article is distributed under a Creative Commons Attribution

(CC-BY) 3.0 license

\title{
Optimized High Frequency Signal Injection Based Permanent Magnet Synchronous Motor Rotor Position Estimation Applied to Washing Machines
}

\author{
${ }^{1,2}$ Olfa Bel Hadj Brahim Kechiche, ${ }^{1,2}$ Houda Ben Attia Sethom, \\ ${ }^{3}$ Hafedh Sammoud and ${ }^{2}$ Ilhem Slama Belkhodja \\ ${ }^{1}$ Department of Electrical Engineering, University of Carthage, \\ Higher School of Technology and Data Processing (ESTI), Tunis, Tunisia \\ ${ }^{2}$ Department of Electrical Engineering, Laboratory of Electrical Systems, \\ University of Tunis El Manar, National School of Engineers of Tunis (ENIT), Tunis, Tunisia \\ ${ }^{3}$ APPCON Technologies SUARL, Ariana, Tunisia
}

\begin{abstract}
Problem statement: This study investigates a novel optimized scheme of a High Frequency Signal Injection (HFSI) based sensor less technique in order to carry out a precise and robust rotor position error estimation of a Permanent Magnet Synchronous Motor (PMSM) drive designed for washing machines. The study was carried out for standstill condition, where precise position information was required for this application. Approach: In order to get rotor position error information, a PMSM high frequency model was considered in the estimated rotor reference frame $(\mathrm{d}, \mathrm{q})$. The impact of the HFSI technique parameters choice on the PMSM rotor position estimation performance was studied and experimentally tested, under various injection conditions. Results: The experimental results show that the amplitude of the high frequency current, resulting from injection, was not significant to carry out high performance rotor position estimation. In order to improve rotor position estimation performance and robustness, a modified demodulation of the high frequency current resulting from injection was proposed by using a high pass filter amplifier applied to PMSM measured currents. The novel proposed rotor position error extraction scheme was implemented on a dsPIC30F6010A and was experimentally validated on a $1 \mathrm{~kW}$ washing salient pole PMSM. Conclusion: This study presents an improved high frequency voltage injection based sensor less control for Permanent Magnet Synchronous Motor (PMSM) designed for washing machines. The optimal parameters choice of the HFSI technique and the use of a high pass filter amplifier have allowed to take the most of the high frequency injected signal for extracting the rotor position error at standstill, compared to a conventional scheme.
\end{abstract}

Key words: Permanent magnet synchronous motor drives, saliency, sensorless control, standstill, continuous high frequency signal injection, washing machines

\section{INTRODUCTION}

Various concepts for high-performance and robust rotor position estimation of Permanent Magnet Synchronous Motor (PMSM) drives without position sensors have been developed in the two past decades (Boucetta, 2008; Asseu et al., 2011). Nowadays, the use of PMSM drives reaches domestic applications because of their good performances, high efficiency and power density, suitability and shape adaptation to the domestic operating environment (Asseu et al., 2011). This is particularly the case of washing machines, where the use of PMSM drives has been and continues to be very widespread (Zhang et al., 2006; Balazovic and Filka,
2008; Chi et al., 2009). Moreover, for such applications, position sensors associated to PMSM drives are the most expensive and delicate components compared to motors, converters, current sensors and control tools. In addition, position sensors are not easy to mount components, they increase drives size and present more maintenance requirements. In fact, the relatively high cost of position sensors puts a brake to the mass production for such home appliances. Moreover, position sensors are subject to high level mechanical vibrations, noise and load torque variations, due to the washing machines functioning at variable torque-speed conditions and different washing cycles. 


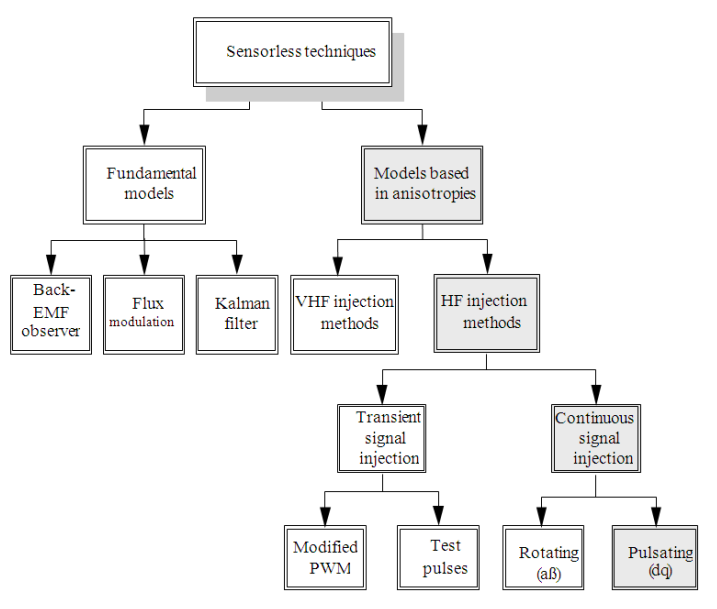

Fig. 1: PMSM sensorless control techniques classification

In order to overcome these limits and insure required torque-speed capabilities and robust operating of washing machines, based on PMSM drives, especially in particular conditions such as very low speeds, standstill, open loop startup and load variation, various sensorless Field Oriented Control techniques have been proposed and developed (Haque et al., 2003; Paramasivam and Arumugam, 2004; Perassi et al., 2005; Taniguchi et al., 2007; Balazovic and Filka, 2008; Sadeghierad et al., 2008; Chi et al., 2009; Feraga et al., 2009; Belie et al., 2010; Vogelsberger et al., 2010; Asseu et al., 2011).

PMSM sensorless control techniques that have been developed by researchers can be classified into two main categories, as it is shown by the Fig. 1 (Kechiche et al., 2011).

The first category includes fundamental modelbased techniques such as Back-EMF Observer, Flux modulation and Kalman Filter, (Paramasivam and Arumugam, 2004; Perassi et al., 2005; Zhang et al., 2006; Jamoussi et al., 2007; Balazovic and Filka, 2008; Boucetta, 2008; George, 2008; Chi et al., 2009; Feraga et al., 2009; Asseu et al., 2011). The second category is interesting in anisotropies model-based techniques (Haque et al., 2003; Perassi et al., 2005; Taniguchi et al., 2007; Hu et al., 2008; Belie et al., 2010). In certain researches, both the first and the second sensorless technique categories are combined in order to cover a wide speed range (Corley and Lorenz, 1998; Perassi et al., 2005; Foo and Rahman, 2010). However, it's very important to note that fundamental model-based techniques don't provide high performances, robustness and a good estimation error at specific operating conditions such as very low speed ranges and standstill, or where a starting torque at standstill is required such as for washing machine applications (Perassi et al., 2005; Hu et al., 2008; Belie et al., 2010). In fact, since back-EMF is zero at standstill and proportional to speed, the measured terminal voltage which has large signal-to-noise ratio cannot detect zero crossing at low speed and standstill, so that the estimated position error is significant at these conditions. However, signal injection schemes can be more efficient at standstill and very low speed than any other sensorless techniques (Haque et al., 2003; Raute et al., 2007; Belie et al., 2010; Vogelsberger et al., 2010). The injected signal can be High Frequency (HF) signal or Very High Frequency (VHF) signal. Techniques based on VHF signal injection have been used in case of nonsalient PMSM.

Different HF signal injection schemes are reported in the literature and can be classified as:

- Transient signal injection based schemes which exploit the PWM signal in order to extract the rotor position or to inject discrete test voltage pulses in a defined direction (Raute et al., 2007; Belie et al., 2010; Vogelsberger et al., 2010)

- Continuous high frequency signal injection based schemes which consist on injection of signal reported to a rotating high frequency voltage vector in the stator reference frame $(\alpha, \beta)$, (Perassi et al., 2005; Hu et al., 2008) or injection of signal reported to a pulsating high frequency voltage vector in a reference frame $(\mathrm{d}, \mathrm{q})$ synchronous with the motor saliency (Aihara et al., 1999; Sakamoto et al., 2001; Holtz, 2008; Wiedmann et al., 2009; Kock et al., 2009)

Transient signal injection schemes are very complex to be implemented for practical real time systems whereas continuous high frequency signal injection schemes are based on a simple excitation and are easier to be experimentally implemented. However, continuous HFSI technique performance and robustness depend on the parameters choice of the high frequency signal injected in order to extract the rotor position or the rotor position error (Taniguchi et al., 2007).

As PMSM drives used in washing machines are characterized by low powers and consequently low currents, then extraction of exploitable high frequency components to achieve rotor position estimation is not made easy. In fact, high frequency components amplitudes, which are proportional to the position rotor estimation error, are not enough significant to be processed by a numerical control unit.

This constitutes the main interest of this study. In fact, the originality of this study is based on an 
optimized HFSI parameters choice according to a novel scheme based on original high-performance extraction of the high frequency injection current. For these purposes, the present study is organized as follows.

First, theoretical background related to the high frequency PMSM model is developed. Then, rotor position estimation scheme in open loop conditions at standstill is presented. Second, the impact of parameters choice of high frequency signal injection on the rotor position error extraction is studied and experimentally tested. The experimental setup includes a $1 \mathrm{~kW}$ PMSM designed for washing machines and a cost-effective 16bit fixed point dsPIC30F6010A digital signal controller.

Finally, a novel scheme to improve the error position extraction, based on the use of a high pass filter amplifier is presented, discussed and experimentally validated.

\section{MATERIALS AND METHODS}

High frequency PMSM model: The salient pole PMSM model used in this study is considered in the (d,q) rotor reference frame, (Boucetta, 2008; Feraga et al., 2009; Kechiche et al., 2011; Asseu et al., 2011), where the d-axis is oriented along the permanent magnet flux and the q-axis is perpendicular to it (Fig. 2).

This model is available in the following conditions:

- The induced EMF is supposed sinusoidal

- The magnetic circuit motor is not saturated and the rotor amortization effect is neglected

- The air-gap irregularities due to stator notches are ignored

- The Eddy currents and hysteresis losses are neglected

- The stator resistances temperature effect is ignored

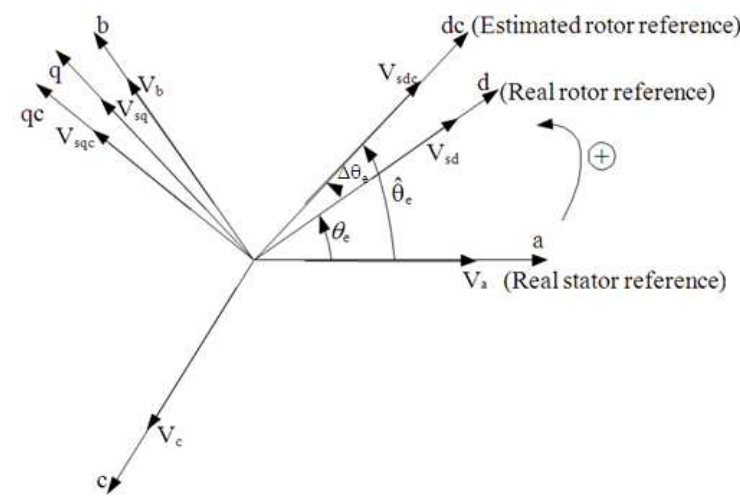

Fig. 2: (a,b,c), (d,q) and (dc, qc) reference frames
In the $(d, q)$ reference frame, the stator voltage components are expressed as follows Eq. 1-3:

$$
\left[\begin{array}{c}
\mathrm{v}_{\mathrm{sd}} \\
\mathrm{v}_{\mathrm{sq}}
\end{array}\right]=\left[\begin{array}{cc}
\left(\mathrm{R}_{\mathrm{s}}+\mathrm{sL}_{\mathrm{sd}}\right) & -\mathrm{L}_{\mathrm{sq}} \omega_{\mathrm{e}} \\
\mathrm{L}_{\mathrm{sd}} \omega_{\mathrm{e}} & \left(\mathrm{R}_{\mathrm{s}}+\mathrm{sL}_{\mathrm{sq}}\right)
\end{array}\right]\left[\begin{array}{l}
\mathrm{i}_{\mathrm{sd}} \\
\mathrm{i}_{\mathrm{sq}}
\end{array}\right]+\left[\begin{array}{l}
0 \\
\psi_{\mathrm{f}} \omega_{\mathrm{e}}
\end{array}\right]
$$

Where:

$$
\begin{aligned}
& \psi_{\text {sd }}=\mathrm{L}_{\mathrm{sd}} \mathrm{i}_{\mathrm{sd}}+\psi_{\mathrm{f}} \\
& \psi_{\mathrm{sq}}=\mathrm{L}_{\mathrm{sq}} \mathrm{i}_{\mathrm{sq}}
\end{aligned}
$$

As the HFSI method consists in injecting a high frequency voltage on the d-axis rotor voltage, it causes magnetic saliency excitation (Aihara et al., 1999; Sakamoto et al., 2001). Then, the HFSI results in high frequency voltage and current components and in an error rotor position $\Delta \theta_{\mathrm{e}}$ defined as Eq. 4 :

$\Delta \theta_{\mathrm{e}}=\theta_{\mathrm{e}}-\hat{\theta}_{\mathrm{e}}$

Where:

$\theta_{\mathrm{e}}=$ The actual rotor position

$\hat{\theta}_{\mathrm{e}}=$ The estimated rotor position

In this case, high frequency voltage and current components can be reported to a (dc,qc) rotor reference frame, which makes $\Delta \theta_{\mathrm{e}}$ with the (d,q) reference frame, as it is shown in Fig. 2.

As the HF injected voltage is expressed by Eq. 5:

$\mathrm{v}_{\mathrm{c}}=\mathrm{V}_{\mathrm{cmax}} \sin \left(\omega_{\mathrm{c}} \mathrm{t}\right)$

Where:

$\omega_{\mathrm{c}}=$ The HF injected voltage pulsation

$\mathrm{V}_{\mathrm{cmax}}=$ The HF injected voltage maximum value

then, the stator voltage equations at high frequency, considered in the $(\mathrm{dc}, \mathrm{qc})$ rotor reference frame, are given by Eq. 6:

$$
\begin{aligned}
& {\left[\begin{array}{l}
\mathrm{v}_{\mathrm{sdc}} \\
\mathrm{v}_{\mathrm{sqc}}
\end{array}\right]=\mathrm{R}_{\mathrm{s}}\left[\begin{array}{l}
\mathrm{i}_{\mathrm{scc}} \\
\mathrm{i}_{\mathrm{sqc}}
\end{array}\right]+\mathrm{j} \omega_{\mathrm{c}}\left[\mathrm{L}_{\mathrm{dqc} 1}\right]\left[\begin{array}{l}
\mathrm{i}_{\mathrm{scc}} \\
\mathrm{i}_{\mathrm{scc}}
\end{array}\right]+} \\
& \mathrm{j} \hat{\mathrm{e}}_{\mathrm{e}}\left[\mathrm{L}_{\mathrm{dqc} 2}\right]\left[\begin{array}{l}
\mathrm{i}_{\mathrm{sdc}} \\
\mathrm{i}_{\mathrm{sqc}}
\end{array}\right]+\omega_{\mathrm{e}} \psi_{\mathrm{f}}\left[\begin{array}{l}
\sin \Delta \theta_{\mathrm{e}} \\
\cos \Delta \theta_{\mathrm{e}}
\end{array}\right]
\end{aligned}
$$

Where:

$\mathrm{v}_{\mathrm{sdc}}$ and $\mathrm{v}_{\mathrm{sqc}}=$ The voltage components resulting from the HFSI 
$\mathrm{i}_{\mathrm{sdc}}$ and $\mathrm{i}_{\mathrm{sqc}}=$ The current components resulting from the HFSI (Fig. 3), inductances matrix $\left[\mathrm{L}_{\mathrm{dqc1}}\right]$ and $\left[\mathrm{L}_{\mathrm{dqc} 2}\right]$ by $(7)$ and $(8)$ as:

$$
\begin{aligned}
& {\left[\mathrm{L}_{\mathrm{dqc} 1}\right]=\left[\begin{array}{ll}
\mathrm{L}_{\mathrm{dc}} & -\mathrm{L}_{\mathrm{dqc}} \\
-\mathrm{L}_{\mathrm{dqc}} & \mathrm{L}_{\mathrm{qc}}
\end{array}\right]} \\
& {\left[\mathrm{L}_{\mathrm{dqc} 2}\right]=\left[\begin{array}{ll}
\mathrm{L}_{\mathrm{dqc}} & -\mathrm{L}_{\mathrm{qc}} \\
\mathrm{L}_{\mathrm{dc}} & \mathrm{L}_{\mathrm{dqc}}
\end{array}\right]}
\end{aligned}
$$

Inductances $\mathrm{L}_{\mathrm{dc}}, \mathrm{L}_{\mathrm{qc}}$ and $\mathrm{L}_{\mathrm{dqc}}$ are defined by (9), (10) and (11) as Eq. 9-13:

$$
\begin{aligned}
& \mathrm{L}_{\mathrm{dc}}=\mathrm{L}_{0}+\mathrm{L}_{1} \cos 2 \Delta \theta_{\mathrm{e}} \\
& \mathrm{L}_{\mathrm{qc}}=\mathrm{L}_{0}-\mathrm{L}_{1} \cos 2 \Delta \theta_{\mathrm{e}} \\
& \mathrm{L}_{\mathrm{dqc}}=\mathrm{L}_{1} \sin 2 \Delta \theta_{\mathrm{e}}
\end{aligned}
$$

Where:

$$
\mathrm{L}_{0}=\frac{\mathrm{L}_{\mathrm{sd}}+\mathrm{L}_{\mathrm{sq}}}{2}
$$

and:

$$
\mathrm{L}_{1}=\frac{\mathrm{L}_{\mathrm{sd}}-\mathrm{L}_{\mathrm{sq}}}{2}
$$

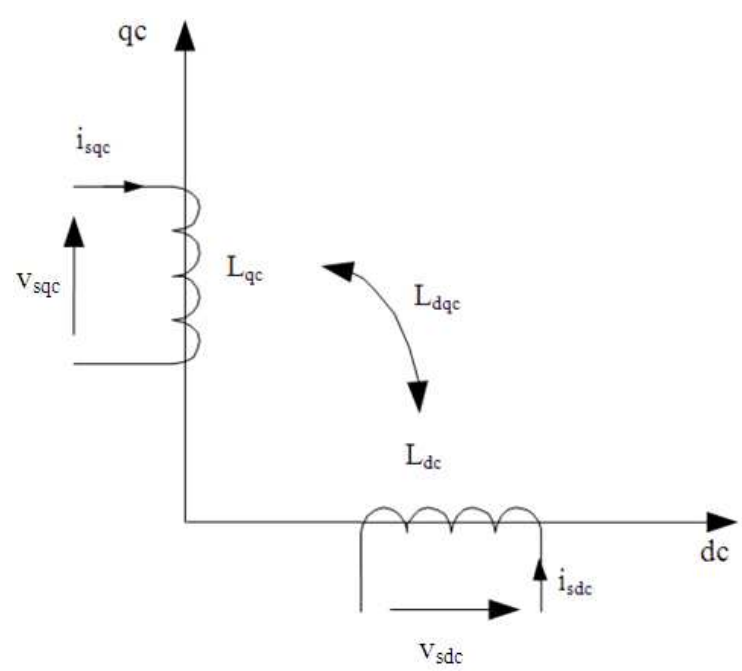

Fig. 3: Voltages, currents and inductances considered in the $(\mathrm{dc}, \mathrm{qc})$ reference frame
Considering the following assumptions (Taniguchi et al., 2007; Balazovic and Filka, 2008):

- The stator resistance $\mathrm{R}_{\mathrm{s}}$ can be neglected compared to the high frequency reactance

- HF injected voltage pulsation $\omega_{c}$ is higher compared to $\omega_{\mathrm{e}}$, so $\omega_{\mathrm{e}}$ is assumed to be neglected.

- The production of the back-EMF is negligible because of rotor vibrations are very small

- Thus, stator voltage equations given by (6) can be approximated as follows Eq. 14:

$$
\left[\begin{array}{c}
\mathrm{v}_{\mathrm{sdc}} \\
\mathrm{v}_{\mathrm{sqc}}
\end{array}\right]=\mathrm{j} \omega_{\mathrm{c}}\left[\begin{array}{ll}
\mathrm{L}_{\mathrm{dc}} & -\mathrm{L}_{\mathrm{dqc}} \\
-\mathrm{L}_{\mathrm{dqc}} & \mathrm{L}_{\mathrm{qc}}
\end{array}\right]\left[\begin{array}{l}
\mathrm{i}_{\mathrm{sdc}} \\
\mathrm{i}_{\mathrm{sqc}}
\end{array}\right]
$$

Then, the PMSM high frequency stator currents, defined in the estimated rotor reference frame (dc,qc) and resulting from (14), are given by Eq. 15:

$\left[\begin{array}{l}i_{\text {sdc }} \\ i_{\text {sqc }}\end{array}\right]=\left[\begin{array}{l}i_{c p}-i_{c n} \cos \left(2 \Delta \theta_{e}\right) \\ i_{c n} \sin \left(2 \Delta \theta_{e}\right)\end{array}\right] \sin \left(\omega_{c} t\right)$

where, $i_{\mathrm{cp}}$ is the HF current vector positive component, proportional to the average value of the $(\mathrm{d}, \mathrm{q})$ stator inductances, given by Eq. 16:

$$
\mathrm{i}_{\mathrm{cp}}=\frac{\mathrm{L}_{0} \mathrm{~V}_{\mathrm{cmax}}}{\mathrm{j} \omega_{\mathrm{c}} \mathrm{L}_{\mathrm{sd}} \mathrm{L}_{\mathrm{sq}}}
$$

and $i_{c n}$ is the HF current vector negative component, proportional to the $(\mathrm{d}, \mathrm{q})$ inductances variation level, given by Eq. 17:

$$
i_{c n}=\frac{L_{1} V_{c \max }}{j \omega_{c} L_{s d} L_{s q}}
$$

Starting from (15), the relation between the carrier current components $i_{\text {sqc }}$ and $i_{\text {sdc }}$ and the rotor position error $\Delta \theta_{\mathrm{e}}$ is highlighted. Then, it is well shown that saliency effects are necessary to estimate the rotor position considering the HFSI technique. Moreover, Eq. 15 shows that the carrier current component $i_{\text {sqc }}$ is directly proportional to the rotor position error $\Delta \theta_{\mathrm{e}}$ (Linke et al., 2003). Then, it is easier to extract the rotor position from $\mathrm{i}_{\mathrm{sqc}}$ than from $\mathrm{i}_{\mathrm{sdc}}$ (Wu et al., 2007) using the Eq. 18:

$$
\mathrm{i}_{\mathrm{sqc}}=\mathrm{i}_{\mathrm{cn}} \sin \left(2 \Delta \theta_{\mathrm{e}}\right) \sin \left(\omega_{\mathrm{c}} \mathrm{t}\right)
$$


Am. J. Engg. \& Applied Sci., 4 (3): 390-399, 2011

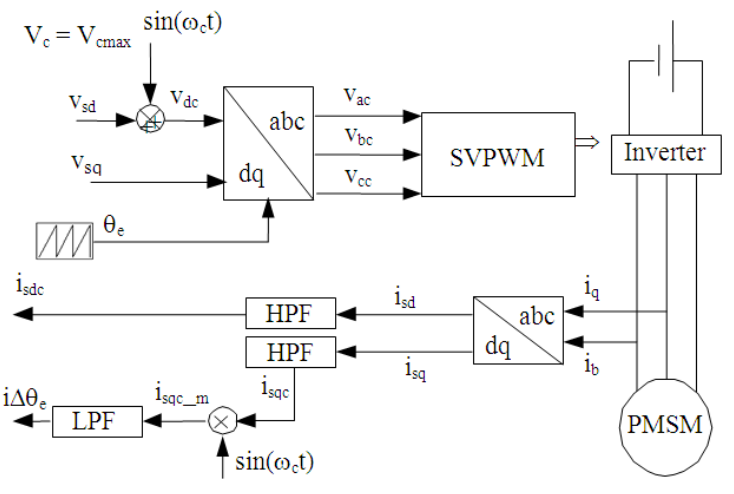

Fig. 4: PMSM rotor position error estimation scheme using HFSI technique

Carrier current demodulation: In order to extract the position error $\Delta \theta_{\mathrm{e}}$ from (18), $\mathrm{i}_{\mathrm{sqc}}$ must be demodulated. In a first step, this demodulation will be carried out in open loop conditions (Kechiche et al., 2011).

The demodulation scheme principle is shown in Fig. 4. First, $i_{\mathrm{sq}}$ is filtered using a High-Pass Filter (HPF) in order to obtain the current signal $i_{\text {sqc }}$, oscillating at the signal injection frequency $\mathrm{f}_{\mathrm{c}}$. Second, the current signal $i_{\text {sqc }}$ is demodulated by multiplying it by a sinusoidal signal at the same frequency as the carrier. The obtained signal, noted $i_{\mathrm{sqc} \_}$, is given by the Eq. 19:

$$
\begin{aligned}
\mathrm{i}_{\mathrm{sqc} \_\mathrm{m}} & =\mathrm{i}_{\mathrm{sqc}} \sin \left(\omega_{\mathrm{c}} \mathrm{t}\right) \\
& =\frac{\mathrm{i}_{\mathrm{cn}}}{2} \sin \left(2 \Delta \theta_{\mathrm{e}}\right)-\frac{\mathrm{i}_{\mathrm{cn}}}{2} \sin \left(2 \Delta \theta_{\mathrm{e}}\right) \cos \left(2 \omega_{\mathrm{c}} \mathrm{t}\right)
\end{aligned}
$$

$\mathrm{i}_{\mathrm{sqc} \_\mathrm{m}}$ is then low-pass filtered in order to extract the signal containing the rotor position error, noted $i_{\Delta \theta e}$. Finally, as $\Delta \theta_{\mathrm{e}}$ must be neighborhood zero, then $\mathrm{i}_{\Delta \theta \mathrm{e}}$ can be approximated by (20) (Wu et al., 2007; Foo and Rahman, 2010) Eq. 20:

$$
\mathrm{i}_{\Delta \theta_{\mathrm{e}}}=\mathrm{i}_{\mathrm{cn}} \Delta \theta_{\mathrm{e}}
$$

Therefore, the estimated rotor position can be obtained by adjusting $i_{\Delta \theta \mathrm{e}}$ to zero.

In order to carry out a high-performance rotor position error extraction at standstill, it is necessary to study the HF voltage parameters choice and its impact on the position error estimation under these conditions.

Experimental setup: An experimental setup has been used in order to study the impact of the injected signal frequency choice on the position error estimation at standstill conditions.

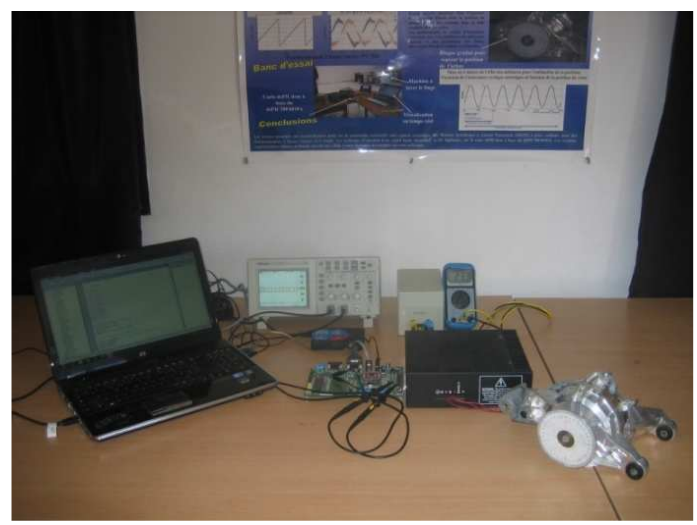

Fig. 5: Experimental setup

The experimental setup, shown by Fig. 5, is composed of:

- A three-phase Interior PMSM, designed for washing machines, which parameters are:

Pole pairs:

3

Rated power $[\mathrm{kW}]$ :

Rated current $[\mathrm{A}]$ :

Rotor magnet flux [Wb]:

Stator resistance $[\Omega]$ :

$\mathrm{d}$ and $\mathrm{q}$-axis inductances $[\mathrm{mH}]$ :

$15.5 / 18.4$

- A dsPICDEM ${ }^{\mathrm{TM}} \mathrm{MC} 1 \mathrm{H}$ three-phase high voltage power Module optimized for three-phase motor applications that require DC bus voltages up to $400 \mathrm{~V}$ and can deliver up to $1 \mathrm{~kW}$ power output. This power module integrates a power inverter and three Hall-effect current sensors. It operates directly from the AC line voltage. The switching frequency of the inverter is of $20 \mathrm{kHz}$. It's important to note that for this domestic application, the DC link voltage is set to $325 \mathrm{~V}$.

- $\quad$ A dsPICDEM ${ }^{\mathrm{TM}}$ MC1 Motor Control Development Board based on 16-bit fixed-point dsPIC30F6010A with $7.3728 \mathrm{MHz}$ as external clock frequency. The Analog to Digital Converter (ADC) associated to this dsPIC is a 10-bit 1Msps converter.

Both Space Vector Pulse Width Modulation (SVPWM) algorithm, used for the motor control and HFSI scheme algorithm are implemented on the dsPIC30F6010A of the dsPICDEM Board.

The HFSI scheme is based on the use of a digital firstorder High-Pass (HP) Infinite Impulse Response (IIR) filter and a digital first-order Low-Pass (LP) IIR filter. 
Am. J. Engg. \& Applied Sci., 4 (3): 390-399, 2011
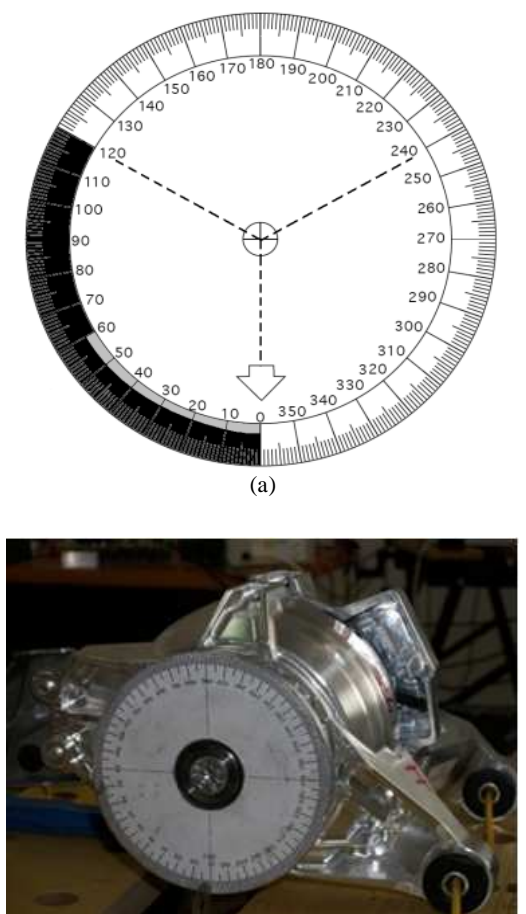

(b)

Fig. 6: Position-graduated disk mounted on the PMSM The position precision offered by the disk is of $1^{\circ}$; (a) Position-graduated Disk; (b) Positiongraduated disk associated to the PMSM axe

Figure 6 shows a view of the Interior PMSM fitted out with a position-graduated disk, mounted on the PMSM axe. The black arc shown by Fig. 6a presents an electrical period of $\left[0^{\circ}, 120^{\circ}\right]$, according to the PMSM poles pairs number equal to 3 . So, this electrical period corresponds to the third of a mechanical period. As an electrical winding is composed of two magnetic poles, then a magnetic period corresponds to $\left[0^{\circ}, 60^{\circ}\right]$.

\section{RESULTS}

Basing on the HFSI technique principle and the experimental setup described previously, several experimental tests were carried out to choose the optimum amplitude and frequency of the injected voltage in order to obtain high performance position error estimation. All the measured currents will be given according to the magnetic position.

In order to obtain a very low position error, it is important to choose carefully the amplitude and the frequency of the injected voltage $\mathrm{v}_{\mathrm{c}}$. These points have been treated by different researches such as (Haque et al., 2003; Taniguchi et al., 2007; Kock et al., 2009; Foo and Rahman, 2010). But, the originality of this study focuses on optimal HFSI parameters choice concerning washing machine applications according to their specific characteristics.

The lower limit of the injected signal frequency is dictated by the need of sufficient spectral separation from the stator current low frequency band, related to the fundamental component and also by the motor noise limitation. The upper limit of the injected signal frequency is dictated by the need of sufficient spectral separation from the stator current high frequency band related to the PWM components.

According to these two limits, the carrier frequency can vary between $200 \mathrm{~Hz}$ and $3 \mathrm{kHz}$.

As the rotor position error is directly proportional to the injected signal amplitude and then this amplitude should be set high enough to achieve the required estimation performance. Moreover, this amplitude is typically chosen about $10-25 \%$ of the DC link voltage level in order to not affect the motor fundamental voltage (Haque et al., 2003; Taniguchi et al., 2007; Balazovic and Filka, 2008; Bianchi and Bolognani, 2009).

In order to choose the optimum injected voltage frequency, several tests have been carried out at different frequencies which are $200 \mathrm{~Hz}, 400 \mathrm{~Hz}, 600 \mathrm{~Hz}$, $1 \mathrm{kHz}$ and $2 \mathrm{kHz}$. For these tests, the optimum injected signal amplitude obtained has been of $57 \mathrm{~V}$, which represents $18 \%$ of the DC link voltage level.

The following experimental results and conclusions have been reached:

- Injected signal frequencies below $400 \mathrm{~Hz}$ perturb the washing machine drive operating. In fact, when using HFSI method for carrying out high performance position estimation, it is necessary to take into account the phenomena of hysteresis magnetic materials and the Eddy currents induced by flux variation in these materials ( $\mathrm{Hu}$ et al., 2008). These phenomena are characterized by low frequencies, then it is necessary to avoid use of frequencies below $400 \mathrm{~Hz}$ as signal injection ones.

- Injected signal frequencies over $2 \mathrm{kHz}$ cannot be well filtered because of presence of HF motor phenomena. Then, it's necessary to avoid use of such frequencies as signal injection ones

- Injected signal frequencies around $400 \mathrm{~Hz}$ make high audible motor noise

- The injected signal frequency $600 \mathrm{~Hz}$ gives better high frequency filtered currents than those obtained with the injected signal frequency $1 \mathrm{kHz}$. In fact, for these two cases, both low frequencies and high frequencies motor phenomena are avoided 

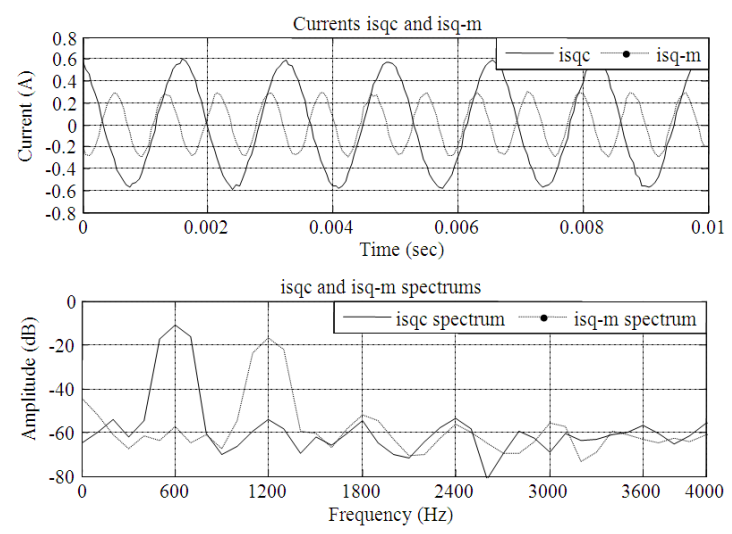

Fig. 7: $i_{\text {sqc }}, i_{\text {sqc } \_m}$ and their spectrums for $f_{c}=600 \mathrm{~Hz}$
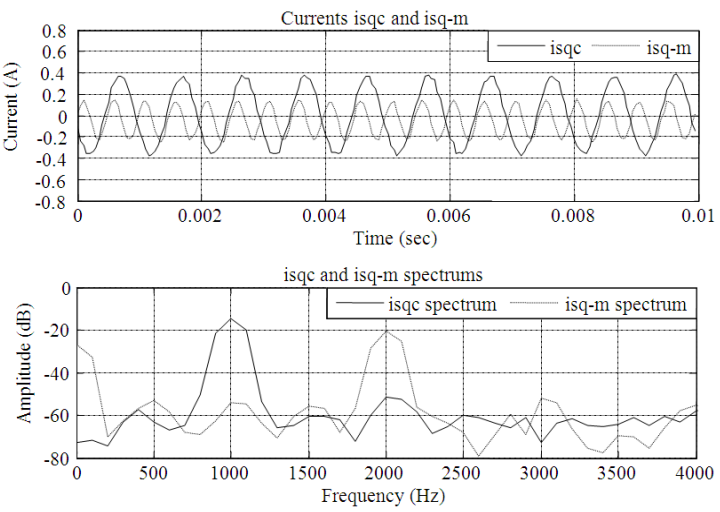

Fig. 8: $i_{\text {sqc }}, i_{\text {sqc } \_m}$ and their spectrums for $f_{c}=1 \mathrm{kHz}$

According to these conclusions, the injected voltage frequencies can vary in the optimal range $[600$ $\mathrm{Hz}$ and $1 \mathrm{kHz}$. The frequencies retained for experimental results are $600 \mathrm{~Hz}$ and $1 \mathrm{kHz}$.

The HFSI technique applied for the position error estimation at standstill has been tested experimentally according to the parameters choice previously proposed:

- Injected signal amplitude: $57 \mathrm{~V}$

- Injected signal frequencies: $600 \mathrm{~Hz}$ and $1 \mathrm{kHz}$

According to Eq. 18, $\mathrm{i}_{\text {sqc }}$ is used to extract the position error $\Delta \theta_{\mathrm{e}}$ after its demodulation. Experimental results are focused on the demodulated high frequency signal injection current $i_{\text {sqc }}$ and its spectrum for the two frequencies $600 \mathrm{~Hz}$ and $1 \mathrm{kHz}$.

Figure 7 and 8 give the currents $i_{\text {sqc }}$ and $i_{\text {sqc } \_m}$ and their spectrums respectively for the two frequencies 600 $\mathrm{Hz}$ and $1 \mathrm{kHz}$. Both the signal $i_{\text {sqc } \_m}$ and its frequency component at the carrier frequency highlight that the amplitude of the modulated current is divided by two, which verifies the analytical Eq. 19.

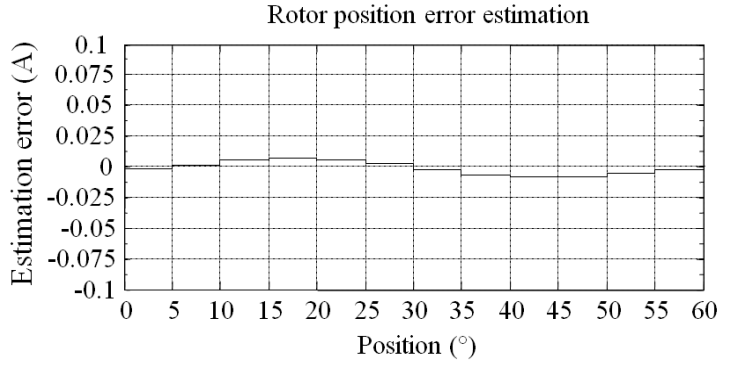

Fig. 9: Rotor position error estimation $i_{\Delta \theta e}$ at standstill for $\mathrm{f}_{\mathrm{c}}=1 \mathrm{kHz}$

Figure 9 presents the evolution of the rotor position error $\mathrm{i}_{\Delta \theta \mathrm{e}}$ related to the injected signal frequency $1 \mathrm{kHz}$.

\section{DISCUSSION}

Impact of the injected voltage frequencies on the position error estimation at standstill: The results obtained with $600 \mathrm{~Hz}$ as injected frequency are better and more exploitable than those obtained with $1 \mathrm{kHz}$. In fact, the amplitude of the frequency component at 600 $\mathrm{Hz}$, which is of $0.29 \mathrm{~A}$, is more significant than the amplitude of the frequency component at $1 \mathrm{kHz}$, which is of $0.18 \mathrm{~A}$. But, the acquisition and data processing environment does not allow such amplitude values processing. Then, performances will be less insured if the injected frequency increases over $600 \mathrm{~Hz}$.

The previous tests have shown that the current resulting from the modulation is still not enough to extract precisely the rotor position error $i_{\Delta \theta e}$, which is varying between $-8 \mathrm{~mA}$ and $8 \mathrm{~mA}$, using the proposed method. Consequently, the injected signal $\mathrm{v}_{\mathrm{c}}$ cannot allow a reliable detection of the rotor position error.

Then, a novel scheme is proposed and developed in order to amplify the amplitude of the current resulting from the injection procedure, which will allow the improvement of the rotor position extraction.

Novel scheme to improve the position error precision at standstill: In order to improve the rotor position error extraction at standstill, a modified HF current demodulation is proposed. In fact, the novel demodulation scheme suggests the use of a High Pass Filter (HPF) operational amplifier, in order to extract the $q$-axis carrier current $i_{\text {sqc }}$ and to amplify it.

The originality of this study is that the amplification and the high pass filtering are applied to the measured PMSM currents after the voltage injection operation, as it is shown by Fig. 10 . 


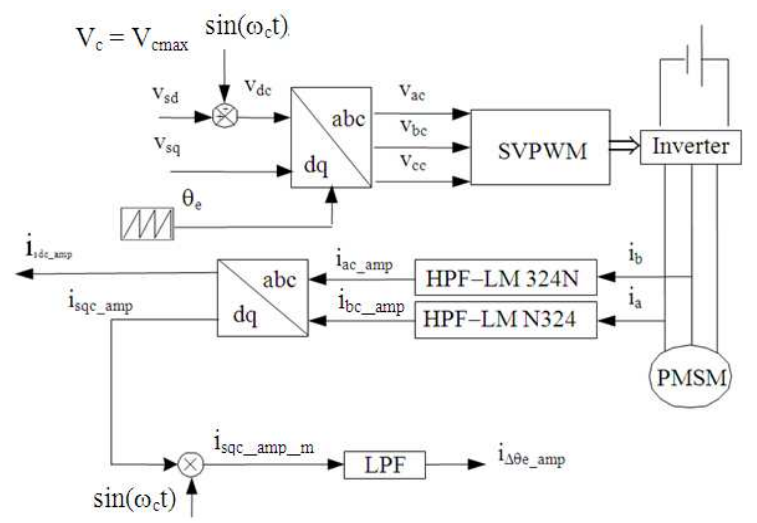

Fig. 10: The novel HF injected current demodulation scheme principle

In order to validate the efficiency of this novel demodulation scheme at standstill, the position error extraction has been tested experimentally taking into account the injection parameters previously proposed:

- Injected signal amplitude: $57 \mathrm{~V}$

- Injected signal frequencies: $600 \mathrm{~Hz}$ and $1 \mathrm{kHz}$

Experimental results are focused on the demodulated high frequency signal injection current $i_{\text {sqc_amp }}$ at standstill, using the novel demodulation scheme.

The measured currents are given according to the magnetic position. The following experimental results and conclusions have been reached:

- $\quad$ The HPF operational amplifier introduces a phase shift between $i_{\text {sqc }}$ and $i_{\text {sqc_amp. }}$. However, according to the Eq. 20, this phase shift has not an influence on the rotor position error extraction

- According to the frequency and the saturation behavior of the HPF operational amplifier, the $i_{\text {sqc }}$ current related to the injected signal frequency 600 $\mathrm{Hz}$ is amplified twice times whereas the $\mathrm{i}_{\text {sqc }}$ current related to the injected signal frequency $1 \mathrm{kHz}$ is amplified four times

Then, it can be concluded that both $600 \mathrm{~Hz}$ and 1 $\mathrm{kHz}$ frequencies give better useful signals for the rotor position error extraction, by considering this novel demodulation scheme. But, experimental trails show that the injected signal frequency $600 \mathrm{~Hz}$ causes more high audible noise than which caused by the injected signal frequency $1 \mathrm{kHz}$. In fact, it's important to note that for such domestic application, the noise generated by a washing machine should to be reduced.
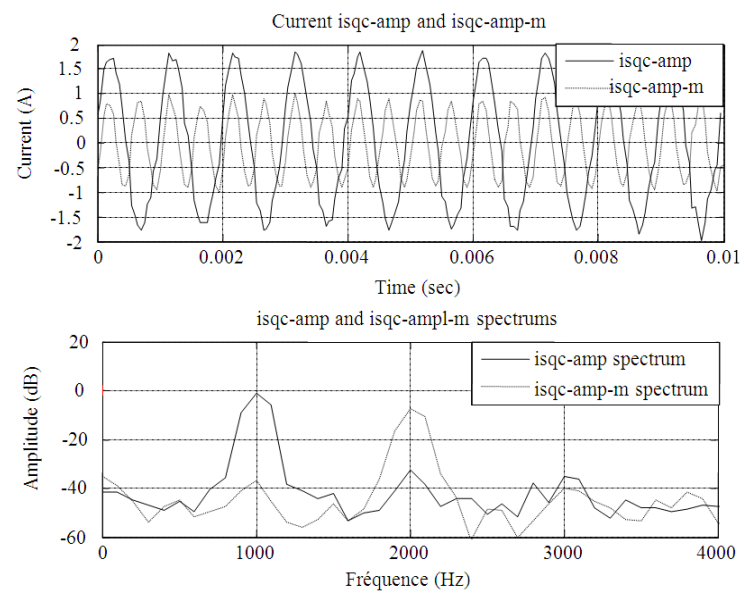

Fig. 11: $i_{\text {sqc_amp }}, i_{\text {sqc_amp_m }}$ and their spectrums for $f_{c}=1 \mathrm{kHz}$

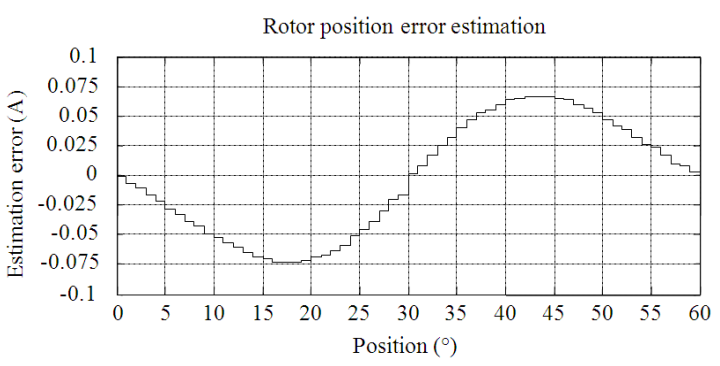

Fig. 12: Rotor position error estimation at standstill using the novel demodulation scheme for $\mathrm{f}_{\mathrm{c}}=1 \mathrm{kHz}$

Finally, it's possible to obtain good rotor position estimation when considering a $1 \mathrm{kHz}$ injected voltage frequency. This frequency has then been retained to carry out experimental validation. Figure 11 gives the current $i_{\text {sqc amp }}$ and $i_{\text {sqc amp } m \text { m }}$ and their spectrums for the frequency $1 \mathrm{kHz}$.

Both the signal $i_{\text {sqc_amp_m }}$ and its frequency component at the carrier frequency highlight that the amplitude of the modulated current, which is of $0.88 \mathrm{~A}$, is well amplified compared to the preceding current $\mathrm{i}_{\text {sqc_m} \text {. }}$

Figure 12 presents the rotor position error $i_{\Delta \theta e \text { amp }}$ evolution after applying the novel demodulation scheme.

The previous tests have shown that the current resulting from the modulation is enough significant to extract precisely the rotor position error $i_{\Delta \theta e}$, which is varying between $-75 \mathrm{~mA}$ and $75 \mathrm{~mA}$, using the proposed novel demodulation scheme.

Then the estimation precision is of $1^{\circ}$, where the precision of the conventional method is of $5^{\circ}$. The experimental results obtained with a three-phase 
Interior PMSM designed for washing machines, confirm performances of the HFSI parameters choice combined to the proposed novel demodulation scheme to estimate the rotor position.

\section{CONCLUSION}

This study presents an improved high frequency voltage injection based sensorless control for Permanent Magnet Synchronous Motor (PMSM) designed for washing machines.

The studies carried out have highlighted the importance of the parameters choice of the HFSI technique in order to take the most of the high frequency injected signal for extracting the rotor position error at standstill.

For this purpose, a high pass filter operational amplifier has been used to extract the q-axis current and to amplify it, before the demodulation of the high frequency q-current component.

The proposed novel scheme has been tested for a $1 \mathrm{~kW}$ salient pole PMSM, designed for washing machines, by using a cost-effective 16-bit dsPIC30F6010A digital signal controller.

The experimental results have proved the rotor position error extraction improvement at standstill, compared to a conventional scheme.

The novel demodulation scheme based on the introducing of the HPF amplifier provides a better rotor position error extraction starting from high frequency injected currents. This is promising to provide a better robustness to the washing machine appliance.

\section{ACKNOWLEDGMENT}

This research project was supported by the Tunisian Ministry of High Education and Scientific Research.

\section{REFERENCES}

Aihara, T., A. Toba, T. Yanase, A. Mashimo and K. Endo, 1999. Sensorless torque control of salientpole synchronous motor at zero-speed operation. IEEE Trans. Power Elect., 14: 202-208. DOI: 10.1109/63.737609

Asseu, O., T.R. Ori, K.E. Ali, Z. Yeo and S. Ouattara et al., 2011. Nonlinear feedback linearization and observation algorithm for control of a permanent magnet synchronous machine. Asian J. Applied Sci., 4: 202-210. DOI: 10.3923/ajaps.2011.202.210
Balazovic, P. and R. Filka, 2008. Sensorless PMSM control for $\mathrm{H}$-axis washing machine drive. Proceedings of the IEEE Power Electronics Specialists Conference, Jun. 15-19, IEEE Xplore Press, Rhodes, pp: 4237-4242. DOI: 10.1109/PESC.2008.4592622

Bianchi, N. and S. Bolognani, 2009. Sensorlessoriented design of PM Motors. IEEE Trans. Indus. Appli., 45: 1249-1257. DOI: 10.1109/TIA.2009.2023387

Boucetta, A., 2008. Vector control of a variable reluctance machine stator and rotor discs imbricates. Am. J. Eng. Applied Sci., 1: 260-265. DOI: 10.3844/ajeassp.2008.260.265

Belie, F.M.L.D., P. Sergeant and J.A. Melkebeek, 2010. A sensorless drive by applying test pulses without affecting the average-current samples. IEEE Trans. Power Elect., 25: 875-888. DOI: 10.1109/TPEL.2009.2036617

Chi, S., Z. Zhang and L. Xu, 2009. Sliding-mode sensorless control of direct-drive PM Synchronous motors for washing machine applications. IEEE Trans. Indus. Appli., 45: 582-590. DOI: 10.1109/TIA.2009.2013545

Corley, M.J. and R.D. Lorenz 1998. Rotor position and velocity estimation for a salient-pole permanent magnet synchronous machine at standstill and high speeds. IEEE Trans. Indus. Appli., 34: 784-789. DOI: $10.1109 / 28.703973$

Feraga, C.E., A. Moussaoui, A. Bouldjedri and A. Yousfi, 2009. Robust position controller for a permanent magnet synchronous actuator. Am. J. Eng. Applied Sci., 2: 388-392. DOI: 10.3844/ajeassp.2009.388.392

Foo, G. and M.F. Rahman, 2010. Sensorless slidingmode MTPA control of an IPM synchronous motor drive using a sliding-mode observer and HF signal injection. IEEE Trans. Indus. Elect., 57: 12701278. DOI: $10.1109 /$ TIE.2009.2030820

George, M., 2008. Speed control of separately excited DC motor. Am. J. Applied Sci., 5: 227-233. DOI: 10.3844/ajassp.2008.227.233

Haque, M.E., L. Zhong and M.F. Rahman, 2003. A sensorless initial rotor position estimation scheme for a direct torque controlled interior permanent magnet synchronous motor drive. IEEE Trans. Power Elect., 18: 1376-1383. DOI: 10.1109/TPEL.2003.818869

Holtz, J., 2008. Acquisition of position error and magnet polarity for sensorless control of PM Synchronous Machines. IEEE Trans. Indus. Appli., 44: 1172-1180. DOI: 10.1109/TIA.2008.921418 
Hu, J., J. Liu and L. Xu, 2008. Eddy current effects on rotor position estimation and magnetic pole identification of PMSM at zero and low speeds. IEEE Trans. Power Elect., 23: 2565-2575. DOI: 10.1109/TPEL.2008.2002087

Jamoussi, K., M. Ouali and H. Charradi, 2007. A sliding mode speed control of an induction motor. Am. J. Applied Sci., 4: 987-994. DOI: 10.3844/ajassp.2007.987.994

Kock, H.W.D., M.J. Kamper and R.M. Kennel, 2009. Anisotropy comparison of reluctance and PM Synchronous Machines for position sensorless control using HF carrier injection. IEEE Trans. Power Elect., 24: 1905-1913. DOI: 10.1109/TPEL.2009.2017537

Kechiche, O.B.H.B., H.S. Attia, H. Sammoud and I.S. Belkhodja, 2011. Continuous HFSI techniques applied to rotor position estimation of IPMSM at standstill and low speed-a survey. Proceedings of the 8th International Multi-Conference on Systems, Signals and Devices, Mar. 22-25, IEEE Xplore Press, Sousse, pp: 1-10. DOI: 10.1109/SSD.2011.5767455

Linke, M., R. Kennel and J. Holtz, 2003. Sensorless speed and position control of synchronous machines using alternating carrier injection. Proceedings of the IEEE International Conference Electric Machines and Drives, Jun. 1-4, IEEE Xplore Press, Germany, pp: 1211-1217. DOI : 10.1109/IEMDC.2003.1210394

Paramasivam, S. and R. Arumugam, 2004. Real time hybrid controller implementation for switched reluctance motor drive. Am. J. Applied Sci., 1: 284-294. DOI: 10.3844/ajassp.2004.284.294

Perassi, H., G. Berger and J. Petzoldt, 2005. Practical implementation of the sensorless field oriented control of a PMSM for wide speed range. Proceedings of the Power Electronics and Applications European Conference (PEAEC'05), IEEE Xplore Press, Dresden, pp: 7-7. DOI: 10.1109/EPE.2005.219552

Raute, R., C. Caruana, J. Cilia, C.S. Staines and M. Sumner, 2007. A zero speed operation sensorless PMSM drive without additional test signal injection. Proceedings of the European Conference Power Electronics and Applications, Sept. 2-5, IEEE Xplore Press, Aalborg, pp: 1-10. DOI: 10.1109/EPE.2007.4417632
Sadeghierad, M., A. Darabi, H. Lesani and H. Monsef, 2008. Design analysis of high-speed axial-flux generator. Am. J. Eng. Applied Sci., 1: 312-317. DOI: 10.3844/ajeassp.2008.312.317

Sakamoto, K., Y. Iwaji, T. Endo and T. Takakura, 2001. Position and speed sensorless control for PMSM drive using direct position error estimation. Proceedings of the 27th Annual Conference of the IEEE Industrial Electronics Society, IEEE Xplore Press, Denver, CO. USA., pp: 1680-1685. DOI: 10.1109/IECON.2001.975540

Taniguchi, S., S. Wakao, K. Kondo and T. Yoneyama, 2007. Position sensorless control of Permanent Magnet Synchronous Motor at low speed range using harmonic voltage injection. Proceedings of the European Conference Power Electronics and Applications, Sept. 2-5, IEEE Xplore Press, Aalborg, $\quad$ pp: 1-7. DOI: 10.1109/EPE.2007.4417470

Vogelsberger, M.A., S. Grubic, T.G. Habetler and T.M. Wolbank, 2010. Using PWM-Induced transient excitation and advanced signal processing for zerospeed sensorless control of AC machines. IEEE Tran. Indus. Elect., 57: 365-374. DOI: 10.1109/TIE.2009.2029578

Wu, S., Y. Li and X. Miao, 2007. Comparison of signal injection methods for sensorless control of PMSM at very low speeds. Proceedings of the European Conference Power Electronics and Applications, Sept. 2-5, IEEE Xplore Press, Aalborg, pp: 1-6. DOI: 10.1109/EPE.2007.4417540

Wiedmann, K., F. Wallrapp and A. Mertens, 2009. Analysis of inverter nonlinearity effects on sensorless control for permanent magnet machine drives based on High-Frequency Signal Injection. Proceedings of 13th European Conference Power Electronics and Applications, Sept. 8-10, IEEE Xplore Press, Barcelona, pp: 1-10.

Zhang, Z., H. Xu, L. Xu and L.E. Heilman, 2006. Sensorless direct field-oriented control of threephase induction motors based on "Sliding Mode" for washing-machine drive applications. IEEE Trans. Indus. Appli., 42: 694-701. DOI: 10.1109/TIA.2006.872919 